\title{
Heart rate variability as a potential diagnostic tool to predict compensatory hyperhidrosis after sympathectomy in patients with primary focal hyperhidrosis
}

\author{
Seong Cheol Jeong ${ }^{1}$, Jae Jun Kim¹, Yong Hwan Kim ${ }^{1}$, In Sub Kim¹, Jung Wook Han ${ }^{1}$, Seok Whan Moon ${ }^{2}$ \\ ${ }^{1}$ Department of Thoracic and Cardiovascular Surgery, Uijeongbu St. Mary's Hospital, The Catholic University of Korea College of Medicine, \\ Uijeongbu, Republic of Korea; ${ }^{2}$ Department of Thoracic and Cardiovascular Surgery, Seoul St. Mary's Hospital, The Catholic University of Korea, \\ College of Medicine, Seoul, Republic of Korea \\ Contributions: (I) Conception and design: SC Jeong, JJ Kim; (II) Administrative support: JJ Kim; (III) Provision of study materials or patients: YH \\ Kim, JW Han; (IV) Collection and assembly of data: IS Kim, SW Moon; (V) Data analysis and interpretation: JJ Kim, SC Jeong; (VI) Manuscript \\ writing: All authors; (VII) Final approval of manuscript: All authors. \\ Correspondence to: Jae Jun Kim, MD, PhD. Department of Thoracic and Cardiovascular Surgery, Uijeongbu St. Mary's Hospital, College of Medicine, \\ The Catholic University of Korea, Geumo-dong, Uijeongbu, Gyeonggi-do, 480-717, Republic of Korea. Email: medkjj@hanmail.net.
}

\begin{abstract}
Background: Primary focal hyperhidrosis $(\mathrm{PFH})$ is associated with autonomic nervous activity, and studies investigating this association in patients with $\mathrm{PFH}$ are very important. Heart rate variability (HRV) is a simple and noninvasive electrocardiographic test showing activity and balance in the autonomic nervous system, which consists of sympathetic and parasympathetic components. The aims of this study are to investigate associations between autonomic nervous activity and hyperhidrosis characteristics using HRV and to investigate the association between HRV findings and compensatory hyperhidrosis $(\mathrm{CH})$ after sympathectomy.
\end{abstract}

Methods: From March 2017 to March 2020, 105 subjects with PFH who underwent preoperative HRV tests and sympathectomy were analyzed. All subjects underwent bilateral thoracoscopic sympathectomy. T2 sympathectomy was conducted for craniofacial hyperhidrosis, and T3 sympathectomy was conducted for palmar hyperhidrosis. The following HRV parameters chosen to investigate the association between hyperhidrosis and autonomic nervous activity were measured by time and frequency domain spectral analysis: (I) time domain: standard deviation of normal-to-normal interval (SDNN) and square root of mean squared differences of successive normal-to-normal intervals (RMSSD), (II) frequency domain: total power (TP) of power spectral density, very low frequency (VLF), low frequency (LF), and high frequency (HF). HRV parameters were analyzed according to hyperhidrosis type (craniofacial vs. palmar type), sweat reduction, and $\mathrm{CH}$ after sympathectomy. In addition, the independent $\mathrm{HRV}$ parameters influencing $\mathrm{CH}$ after sympathectomy were investigated with multivariate analysis.

Results: Craniofacial hyperhidrosis was significantly more prevalent in the old age group $(\mathrm{P}<0.001)$. Sweat reduction after sympathectomy was significantly more prominent in palmar hyperhidrosis $(\mathrm{P}=0.037)$, and $\mathrm{CH}$ after sympathectomy was more prominent in craniofacial hyperhidrosis $(\mathrm{P}<0.001)$. Palmar type patients exhibited significantly larger SDNN, RMSSD, TP, LF, and HF than craniofacial type patients (all $\mathrm{P}<0.001)$. There were no significant differences in any HRV parameters according to sweat reduction after sympathectomy. Low-degree $\mathrm{CH}$ was associated with significantly larger SDNN, RMSSD, TP, LF, and HF than high-degree $\mathrm{CH}(\mathrm{P}<0.001, \mathrm{P}<0.001, \mathrm{P}=0.002, \mathrm{P}=0.001$, and $\mathrm{P}<0.001$, respectively). Multivariate analysis showed that $\mathrm{HF}$ and age group were associated with $\mathrm{CH}$ after sympathectomy $(\mathrm{P}=0.007$ and $\mathrm{P}=0.010$, respectively).

Conclusions: This study shows that HRV can provide useful insight into the pathophysiology of $\mathrm{PFH}$ and enhance preoperative risk stratification of $\mathrm{CH}$. Large-scale, prospective studies are required to determine the predictive value of $\mathrm{HRV}$ in patients at risk for subsequent $\mathrm{CH}$ after sympathectomy. 
Keywords: Compensatory hyperhidrosis (CH); sympathectomy; heart rate variability (HRV)

Submitted May 26, 2020. Accepted for publication Sep 15, 2020.

doi: $10.21037 /$ jtd-20-2038

View this article at: http://dx.doi.org/10.21037/jtd-20-2038

\section{Introduction}

Primary focal hyperhidrosis $(\mathrm{PFH})$ is a common condition characterized as uncontrolled, excessive sweating in symmetric patterns in the hands, axillae, craniofacial region, and feet (1). The pathophysiology of PFH remains unclear, and various etiologies have been suggested $(1,2)$. Minimally invasive thoracoscopic sympathetic blockade is widely accepted for severe $\mathrm{PFH}$ when other medical treatments fail $(2,3)$. This procedure is usually conducted by bilaterally ablating the second and third thoracic sympathetic ganglia with sympathetic efferent to affected areas with or without other procedures (3-5). The outcomes of this procedure are highly satisfactory, but compensatory hyperhidrosis $(\mathrm{CH})$ remains a devastating complication $(4,6)$. The incidence of $\mathrm{CH}$ is very high, occurring in up to $98 \%$ of cases, and results in dissatisfaction with the treatment and regret $(7,8)$. While many studies have tried to overcome $\mathrm{CH}$, it remains problematic $(4,9,10)$.

$\mathrm{PFH}$ is associated with autonomic nervous activity (1,11-16). Heart rate variability (HRV) measures the physiologic variation in time intervals between consecutive instantaneous heart beats in milliseconds $(17,18)$. HRV is a simple and noninvasive electrocardiographic test showing activity and balance of the autonomous nervous system, which consists of sympathetic and parasympathetic components (17-19). Because the second and third sympathetic thoracic ganglia innervating the heart are ablated in sympathectomy, most previous studies have investigated changes in HRV findings after sympathectomy (20-24). However, few studies about associations between autonomic nervous activities, PFH characteristics, and postoperative outcomes have been performed. In particular, the association between autonomic nervous activities and $\mathrm{CH}$ remains unknown $(12,14,22)$. The aims of this study are to investigate associations between autonomic nervous activity and PFH characteristics using HRV and to investigate the association between $\mathrm{HRV}$ findings and $\mathrm{CH}$ after sympathectomy. We present the following article in accordance with the STROBE reporting checklist (available at http://dx.doi.org/10.21037/jtd-20-2038).

\section{Methods}

\section{Subjects and sympatbectomy}

From March 2017 to March 2020, all patients with PFH who underwent preoperative HRV tests and sympathectomy were reviewed. Inclusion criteria for this study were as follows: (I) PFH in the craniofacial region and hands, (II) no previous intrathoracic procedure, (III) no routine administration of medicines, such as antihypertensive drugs, (IV) no alcohol, caffeinated beverages, or smoking one day before HRV test, and (V) no apparent sociopsychological problem. Data on subject characteristics, disease status, operative procedures, and postoperative outcomes were collected using medical chart reviews and telephone inquiries. The telephone inquiry questionnaire consisted of degree of sweat reduction, recurrence of sweat, and degree and localization of $\mathrm{CH}$. Sweat reduction was presented as improvement and a recurrence or failure (no sweat reduction). The degrees of $\mathrm{CH}$ were presented as low (negligible and mild) and high (moderate and severe). Hyperhidrosis type was determined by chief complaint and all subjects underwent bilateral thoracoscopic sympathectomy. T2 sympathectomy was conducted for craniofacial hyperhidrosis and T3 sympathectomy was conducted for palmar hyperhidrosis (4). Postoperative outcomes in all subjects were routinely evaluated one month after sympathectomy.

\section{Measurement of HRV}

HRV tests were performed to investigate the association between PFH and autonomic nervous activity. HRV tests were conducted using the SA-3000P model (Medi-core, Seoul, Korea). Each subject was comfortably seated on a chair, electrodes were positioned on the bilateral wrists and left foot for five minutes to obtain HRV measurements. The subject was guided to breathe as usual during the HRV test. The following HRV parameters chosen for investigation of the association between hyperhidrosis and autonomic nervous activity were measured by time and frequency 
domain spectral analysis $(17,18)$ : (I) time domain: standard deviation of normal-to-normal interval (SDNN) and square root of mean squared differences of successive $\mathrm{NN}$ intervals (RMSSD), (II) frequency domain: total power (TP) of power spectral density in range of frequencies between 0 and $0.4 \mathrm{~Hz}$, very low frequency (VLF) of power spectrum range between 0.0033 and $0.04 \mathrm{~Hz}$, low frequency (LF) of power spectrum range between 0.04 and $0.15 \mathrm{~Hz}$, and high frequency (HF) of power spectrum range between 0.15 and $0.4 \mathrm{~Hz}$.

\section{Statistical considerations and ethical statement}

All data are shown as mean $\pm \mathrm{SD}$. One sample $t$-test is used to determine an autonomic dominance in each group. Student's $t$-tests were conducted to compare groups with continuous independent variables. The chi-square test was performed to investigate relationships between groups with categorical variables. To identify independent influencing parameters for $\mathrm{CH}$, multivariate analysis was performed using the binary logistic regression test (backward method). The results were evaluated using the Statistical Package of Social Sciences version 22.0 (SPSS, IBM Corp., NY, USA) with 0.05 considered the value of significance. Participants gave informed consent before taking part and approval from Uijeongbu Saint Mary's Hospital Ethics Committee was obtained for this study (approval number: UC20RISI0074). The study conformed to the provisions of the Declaration of Helsinki (as revised in 2013).

\section{Results}

A total of 105 ethnically Korean subjects were included in the study. The mean age of study subjects at sympathectomy was $30.1( \pm 15.2)$ years and the mean observation period was 15.3 $( \pm 7.7)$ months. Of included subjects, 61 were male and 44 were female. PFH types included 34 craniofacial and 71 palmar cases. The conventional procedure using two-port thoracoscopic sympathectomy was performed in all cases. Craniofacial hyperhidrosis was significantly more prevalent in the old age group $(\mathrm{P}<0.001)$. Sweat reduction after sympathectomy was significantly more prominent in palmar hyperhidrosis ( $\mathrm{P}=0.037)$, and $\mathrm{CH}$ after sympathectomy was more prominent in craniofacial hyperhidrosis $(\mathrm{P}<0.001)$. The summarized clinical characteristics of study subjects are presented in Table 1.

\section{Association between HRV parameters and PFH types}

There were significant differences in some HRV parameters according to $\mathrm{PFH}$ type. Palmar $\mathrm{PFH}$ was associated with significantly greater SDNN $(\mathrm{P}<0.001)$, RMSSD $(\mathrm{P}<0.001)$, TP $(\mathrm{P}<0.001)$, LF $(\mathrm{P}<0.001)$, and HF $(\mathrm{P}<0.001)$. These findings suggest that autonomic nervous activities differ according to $\mathrm{PFH}$ type. Sympathetic nervous activation dominated in overall subjects $(\mathrm{P}<0.001)$ and in each hyperhidrosis type (both $\mathrm{P}<0.001$ ), while autonomic nervous imbalance was increased in craniofacial type $(\mathrm{P}=0.002)$ (Figure 1 and Table 2). Comparisons of HRV parameters between craniofacial and palmar $\mathrm{PFH}$ are summarized in Table 2.

\section{Association between HRV parameters and sweat reduction after sympathectomy}

The improved group and unchanged or recurrent group contained 100 and 5 subjects, respectively. Associations between sweat reduction and HRV parameters after sympathectomy were analyzed. There was no significant difference in HRV parameters according to sweat reduction after sympathectomy (Table 3).

\section{Association between HRV parameters and CH after sympathectomy}

The low and high groups of $\mathrm{CH}$ contained 78 and 27 subjects, respectively. $\mathrm{CH}$ after sympathectomy was more prominent in craniofacial type $(\mathrm{P}<0.001)$. Associations between $\mathrm{CH}$ and HRV parameters after sympathectomy were analyzed. Some parameters were significantly larger in the low degree of $\mathrm{CH}$ group (SDNN $\mathrm{P}<0.001$, RMSSD $\mathrm{P}<0.001$, TP $\mathrm{P}=0.002$, LF $\mathrm{P}<0.001$, and HF $\mathrm{P}<0.001$ ) than in the high degree of $\mathrm{CH}$ group. Autonomic nervous balance differed according to degree of $\mathrm{CH}(\mathrm{P}=0.033)$ (Table 4 and Figure 2).

\section{Multivariate analysis for the independent influencing factors of $\mathrm{CH}$ using $\mathrm{HRV}$ parameters}

Univariate analysis showed that some time domain factors (SDNN, RMSSD) and frequency domain factors (TP, $\mathrm{LF}$, and HF) were associated with degree of $\mathrm{CH}$. To investigate the independent influencing factors for $\mathrm{CH}$ after sympathectomy, a multivariate analysis was conducted using a binary logistic regression test (backward method). Because HRV parameters are dependent on age and sex, covariates for a binary logistic regression test included significant factors in the univariate analysis, age groups, and sex. The 
Table 1 The overall clinical characteristics of the study subjects

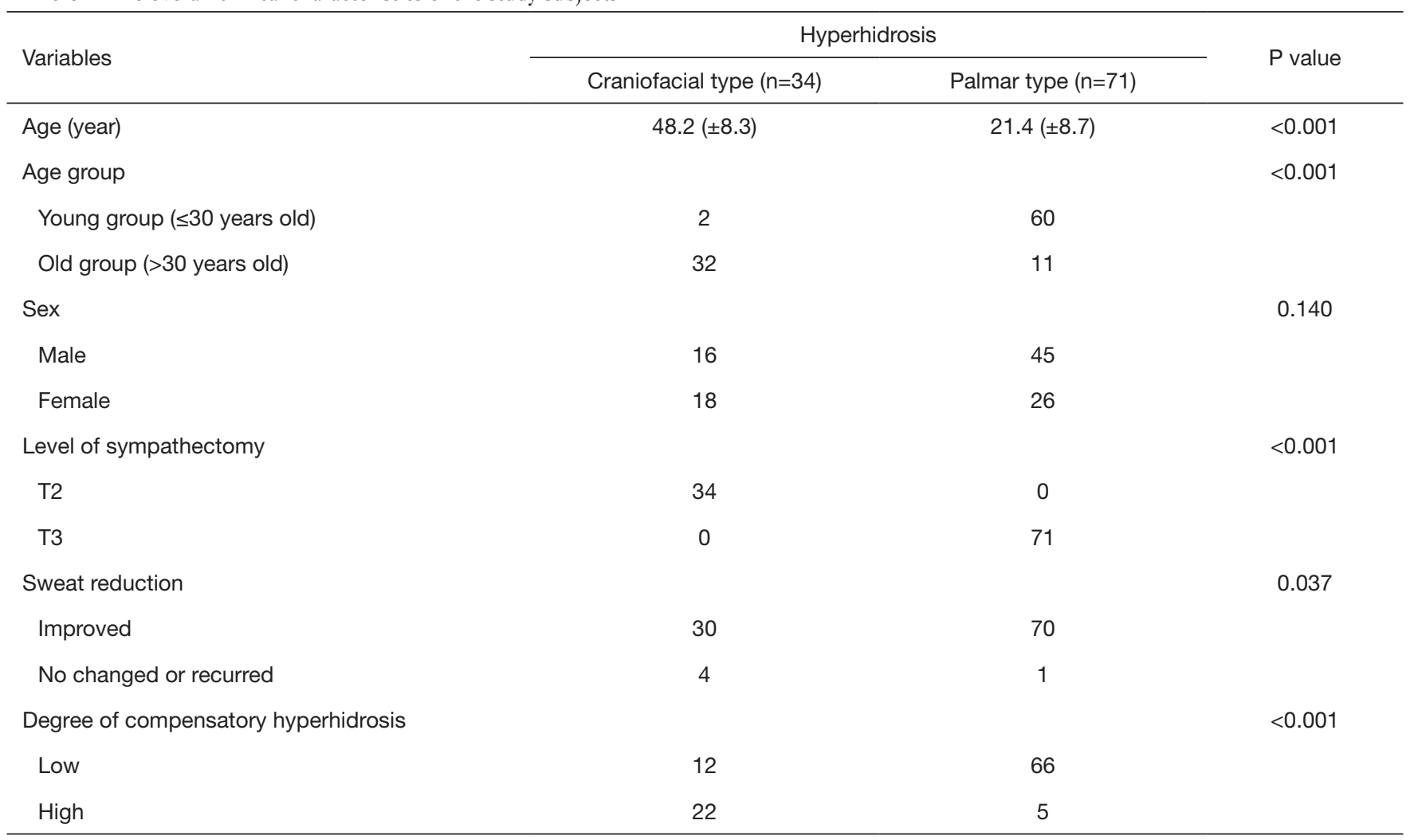

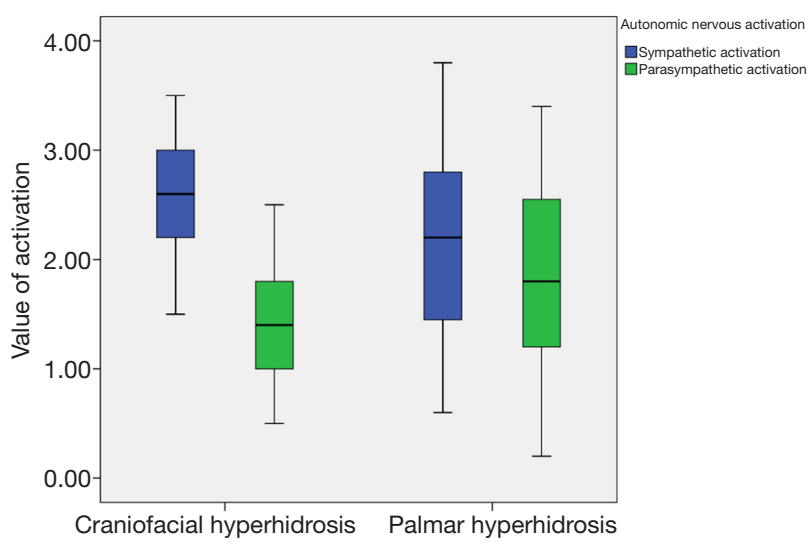

Figure 1 Sympathetic nervous activation is more dominant in overall $\mathrm{PFH}$ and in each primary focal hyperhidrosis type. Sympathetic nervous activation and autonomic nervous unbalance are increased in craniofacial PFH. PFH, primary focal hyperhidrosis. multivariate analysis showed that $\mathrm{HF}$ and age group were associated with $\mathrm{CH}$ after sympathectomy $(\mathrm{P}=0.007$ and $\mathrm{P}=0.010$, respectively) (Table 5).

\section{Discussion}

Although the exact etiology of PFH has not been established, it is thought to be associated with autonomic nervous activity (1,11-16). However, associations between autonomic nervous activity and $\mathrm{PFH}$ remain unclear. Investigations of these associations are required to increase understanding of the characteristics of PFH $(1,21)$. HRV is a physiologic phenomenon reflecting autonomic nervous activities (17-19). HRV is predictive for certain conditions, such as mortality after cardiovascular disease, and prognostic for many other diseases $(17,18,25)$. While previous studies have investigated HRV in PFH, many aspects of HRV in $\mathrm{PFH}$ remain unknown, and its clinical usage in $\mathrm{PFH}$ is very 
Table 2 Comparisons of HRV parameters between craniofacial and palmar type

\begin{tabular}{|c|c|c|c|}
\hline Parameters & \multicolumn{2}{|c|}{ Primary focal hyperhidrosis type } & $P$ value \\
\hline SDNN (ms) & $30.4 \pm 14.2$ & $47.4 \pm 17.0$ & $<0.001$ \\
\hline RMSSD (ms) & $21.4 \pm 12.5$ & $44.5 \pm 22.5$ & $<0.001$ \\
\hline $\mathrm{TP}\left(\mathrm{ms}^{2}\right)$ & $880.2 \pm 824.1$ & $2,066.3 \pm 1,562.3$ & $<0.001$ \\
\hline $\operatorname{LF}\left(m s^{2}\right)$ & $215.9 \pm 214.7$ & $556.1 \pm 439.4$ & $<0.001$ \\
\hline $\mathrm{HF}\left(\mathrm{ms}^{2}\right)$ & $110.4 \pm 113.2$ & $616.5 \pm 715.7$ & $<0.001$ \\
\hline \multicolumn{4}{|c|}{ Autonomic dominance } \\
\hline Sympathetic & 29 & 43 & 0.013 \\
\hline
\end{tabular}

HRV, heart rate variability; SDNN, standard deviation of the normal-to-normal interval; RMSSD, square root of the mean squared differences of successive NN intervals; TP, total power; VLF, very low frequency; LF, low frequency; HF, high frequency.

Table 3 Comparison of HRV parameters according to degree of sweat reduction after sympathectomy

\begin{tabular}{|c|c|c|c|}
\hline Variables & \multicolumn{2}{|c|}{ Sweat reduction } & $P$ value \\
\hline SDNN (ms) & $42.5 \pm 17.9$ & $29.3 \pm 15.4$ & 0.109 \\
\hline RMSSD (ms) & $37.7 \pm 22.6$ & $24.8 \pm 17.8$ & 0.215 \\
\hline $\mathrm{TP}\left(\mathrm{ms}^{2}\right)$ & $1,721.5 \pm 1,488.7$ & $896.9 \pm 862.0$ & 0.223 \\
\hline $\mathrm{LF}\left(\mathrm{ms}^{2}\right)$ & $452.9 \pm 418.0$ & $307.0 \pm 275.6$ & 0.443 \\
\hline $\mathrm{HF}\left(\mathrm{ms}^{2}\right)$ & $470.3 \pm 647.2$ & $98.7 \pm 93.5$ & 0.204 \\
\hline \multicolumn{4}{|c|}{ Autonomic dominance } \\
\hline Sympathetic & 68 & 4 & 0.674 \\
\hline
\end{tabular}

HRV, heart rate variability; SDNN, standard deviation of the normal-to-normal interval; RMSSD, square root of the mean squared differences of successive NN intervals; TP, total power; VLF, very low frequency; LF, low frequency; HF, high frequency.

limited $(14,21,22,24)$.

Despite the outstanding results of sympathectomy, $\mathrm{CH}$ remains the most devastating postoperative complication. $\mathrm{CH}$ has a considerable prevalence rate and is the main cause of dissatisfaction after sympathectomy $(3,4,6,8)$. Many studies have investigated prevention of $\mathrm{CH}$ and suggested risk factors associated with $\mathrm{CH}(4,5,7,9,26)$. Extent, level, and total number of sympathectomy procedures as well as body mass index have been suggested to be associated with $\mathrm{CH}(4,5,7)$. However, $\mathrm{CH}$ is not well understood, and prevention of $\mathrm{CH}$ is essential to manage $\mathrm{PFH}(4,8)$. Because $\mathrm{PFH}$ and autonomic nervous activity are associated, an association between $\mathrm{CH}$ and autonomic nervous activity is also possible. Therefore, it is important to investigate potential associations using HRV. However, no study has used HRV to investigate $\mathrm{CH}$. To the best of our knowledge, this is the first study of $\mathrm{CH}$ after sympathectomy using HRV tests.

The present study showed that $\mathrm{CH}$ and $\mathrm{PFH}$ are definitively associated with autonomic nervous activities. 
Table 4 Comparison of HRV parameters according to degree of compensatory hyperhidrosis after sympathectomy

\begin{tabular}{|c|c|c|c|}
\hline Variables & \multicolumn{2}{|c|}{ Compensatory hyperhidrosis } & $P$ value \\
\hline SDNN (ms) & $45.7 \pm 17.3$ & $31.0 \pm 15.3$ & $<0.001$ \\
\hline RMSSD (ms) & $41.7 \pm 23.2$ & $23.7 \pm 13.5$ & $<0.001$ \\
\hline $\mathrm{TP}\left(\mathrm{ms}^{2}\right)$ & $1,901.9 \pm 1,541.5$ & $1,047.8 \pm 1,038.1$ & 0.002 \\
\hline $\mathrm{LF}\left(\mathrm{ms}^{2}\right)$ & $509.7 \pm 436.4$ & $261.7 \pm 263.0$ & 0.001 \\
\hline $\mathrm{HF}\left(\mathrm{ms}^{2}\right)$ & $566.6 \pm 700.8$ & $123.4 \pm 125.6$ & $<0.001$ \\
\hline \multicolumn{4}{|c|}{ Autonomic dominance } \\
\hline Sympathetic & 49 & 23 & 0.033 \\
\hline
\end{tabular}

$\mathrm{HRV}$, heart rate variability; SDNN, standard deviation of the normal-to-normal interval; RMSSD, square root of the mean squared differences of successive NN intervals; TP, total power; VLF, very low frequency; LF, low frequency; HF, high frequency.

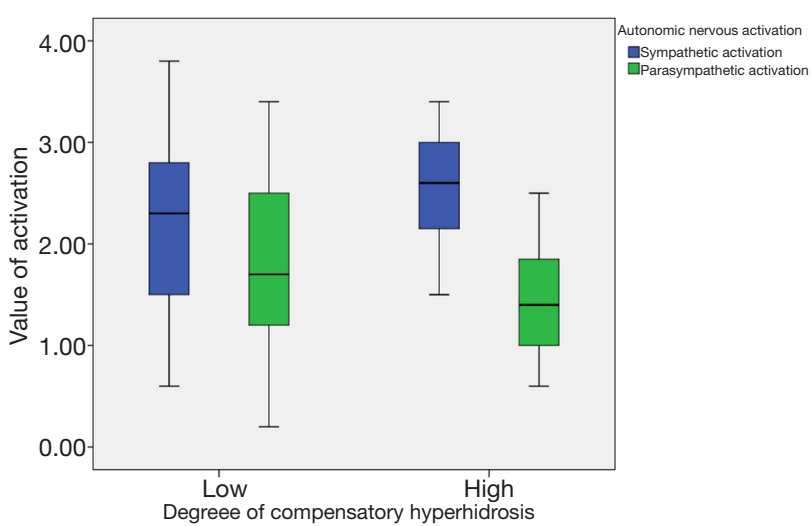

Figure 2 Sympathetic nervous activation dominated in both groups. Autonomic nervous unbalance is increased in the group with high degree of compensatory hyperhidrosis.

First, craniofacial PFH was more prevalent in the old age group. After sympathectomy, sweat reduction was more prominent in palmar type and $\mathrm{CH}$ was more prominent in craniofacial type PFH $(4,7)$. HRV findings suggested that autonomic nervous activation differed according to PFH type. Sympathetic nervous activation and autonomic nervous unbalance were increased in craniofacial PFH. Second, sweat reduction was more prominent in the young group $(4,7,9)$. However, there was no significant association between sweat reduction after sympathectomy and HRV findings. The association was likely not identified due to the high success rate of sympathectomy and small sample size. Third, some HRV parameters were associated with
$\mathrm{CH}$ after sympathectomy. Only HF of HRV parameters and age group were included as significant independent influencing factors for $\mathrm{CH}$ after sympathectomy. HF reflects parasympathetic activity and is known as a 'respiratory' band because it corresponds to $\mathrm{NN}$ variations caused by respiration regulation $(17,18)$. Although sweating secretion is caused by sympathetic nervous activation innervating eccrine sweat glands, this finding shows that parasympathetic regulation or activity is involved in the pathogenesis of $\mathrm{CH}(1,2)$. HRV tests were helpful for prediction of $\mathrm{CH}$ after sympathectomy.

This study has some limitations, including that it was conducted at a single center, was non-randomized, was retrospective, and included a small sample size for many parameters. In addition, the HRV test is influenced by various conditions that may result in statistical errors. We tried to minimize errors by using strict inclusion criteria.

\section{Conclusions}

This study shows that HRV has the considerable potential to supply additional useful insight into the pathophysiology of $\mathrm{PFH}$ and enhance preoperative risk stratification of $\mathrm{CH}$. Large-scale, prospective studies are required to determine the predictive value of $H R V$ in patients at risk for subsequent $\mathrm{CH}$ after sympathectomy. HRV studies on PFH will enhance our understanding of the pathophysiology of $\mathrm{PFH}$, sympathectomy outcomes, and $\mathrm{CH}$ mechanisms. 
Table 5 Multivariate analysis for risk factors of compensatory hyperhidrosis using HRV findings

\begin{tabular}{lccc}
\hline Variables & P value & Odds ratio & 95\% confidence interval \\
\hline TP & 0.062 & 1.001 & $1.000-1.001$ \\
HF & 0.007 & 0.993 & $0.988-0.998$ \\
Old-age group & 0.010 & 4.683 & $1.436-15.270$ \\
\hline
\end{tabular}

$\mathrm{HRV}$, heart rate variability; TP, total power; HF, high frequency.

\section{Acknowledgments}

Funding: None.

\section{Footnote}

Reporting Checklist: The authors have completed the STROBE reporting checklist. Available at http://dx.doi. org/10.21037/jtd-20-2038

Data Sharing Statement: Available at http://dx.doi. org/10.21037/jtd-20-2038

Conflicts of Interest: All authors have completed the ICMJE uniform disclosure form (available at http://dx.doi. org/10.21037/jtd-20-2038). The authors have no conflicts of interest to declare.

Ethical Statement: The authors are accountable for all aspects of the work in ensuring that questions related to the accuracy or integrity of any part of the work are appropriately investigated and resolved. Participants gave informed consent before taking part and approval from Uijeongbu Saint Mary's Hospital Ethics Committee was obtained for this study (Approval number: UC20RISI0074). The study conformed to the provisions of the Declaration of Helsinki (as revised in 2013).

Open Access Statement: This is an Open Access article distributed in accordance with the Creative Commons Attribution-NonCommercial-NoDerivs 4.0 International License (CC BY-NC-ND 4.0), which permits the noncommercial replication and distribution of the article with the strict proviso that no changes or edits are made and the original work is properly cited (including links to both the formal publication through the relevant DOI and the license). See: https://creativecommons.org/licenses/by-nc-nd/4.0/.

\section{References}

1. Schick CH. Pathophysiology of Hyperhidrosis. Thorac Surg Clin 2016;26:389-93.

2. Nawrocki S, Cha J. The etiology, diagnosis, and management of hyperhidrosis: A comprehensive review: Therapeutic options. J Am Acad Dermatol 2019;81:669-80.

3. Bagheri R, Sharifian Attar A, Haghi SZ, et al. Thoracoscopic sympathicotomy in the treatment of palmar hyperhidrosis. Asian Cardiovasc Thorac Ann 2016;24:687-91.

4. Han JW, Kim JJ, Kim YH, et al. New sympathicotomy for prevention of severe compensatory hyperhidrosis in patients with primary hyperhidrosis. J Thorac Dis 2020;12:765-72.

5. Romero FR, Cataneo DC, Cataneo AJM. Outcome of Percutaneous Radiofrequency Thoracic Sympathectomy for Palmar Hyperhidrosis. Semin Thorac Cardiovasc Surg 2018;30:362-6.

6. Du X, Zhu X, Wang T, et al. Compensatory hyperhidrosis after different surgeries at the same sympathetic levels: a meta-analysis. Ann Transl Med 2018;6:203.

7. Yamamoto H, Okada M. The management of compensatory sweating after thoracic sympathectomy. J Thorac Cardiovasc Surg 2019;158:1481-8.

8. Wolosker N, Milanez de Campos JR, Fukuda JM. Management of Compensatory Sweating After Sympathetic Surgery. Thorac Surg Clin 2016;26:445-51.

9. Leiderman DBD, Milanez de Campos JR, Kauffman P, et al. The relation between age and outcomes of thoracic sympathectomy for hyperhidrosis: The older the better. J Thorac Cardiovasc Surg 2018;156:1748-56.

10. Jeong JY, Park HJ, Park JK, et al. Predictive procedure for compensatory hyperhidrosis before sympathectomy: preliminary findings. Thorac Cardiovasc Surg 2014;62:434-8.

11. Freixinet Gilart J, Julia-Serda G, Calderon Murgas CL, et al. Cardiorespiratory Side Effects in the Clipping 
Technique for the Treatment of Axillary and Palmar Hyperhidrosis. Arch Bronconeumol 2018;54:486-7.

12. Chen JP, Chen RF, Peng AJ, et al. Is compensatory hyperhidrosis after thoracic sympathicotomy in palmar hyperhidrosis patients related to the excitability of thoracic sympathetic ganglions? J Thorac Dis 2017;9:3069-75.

13. De Marinis M, Colaizzo E, Petrelli RA, et al. Alterations in cardiovascular autonomic function tests in idiopathic hyperhidrosis. Auton Neurosci 2012;167:34-8.

14. Kaya D, Karaca S, Barutcu I, et al. Heart rate variability in patients with essential hyperhidrosis: dynamic influence of sympathetic and parasympathetic maneuvers. Ann Noninvasive Electrocardiol 2005;10:1-6.

15. Senard JM, Simonetta-Moreau M, Tran MA. Blood pressure and heart rate variability in patients with essential hyperhidrosis. Clin Auton Res 2003;13:281-5.

16. Shih CJ, Wu JJ, Lin MT. Autonomic dysfunction in palmar hyperhidrosis. J Auton Nerv Syst 1983;8:33-43.

17. Singh N, Moneghetti KJ, Christle JW, et al. Heart Rate Variability: An Old Metric with New Meaning in the Era of using mHealth Technologies for Health and Exercise Training Guidance. Part One: Physiology and Methods. Arrhythm Electrophysiol Rev 2018;7:193-8.

18. Shaffer F, Ginsberg JP. An Overview of Heart Rate Variability Metrics and Norms. Front Public Health 2017;5:258.

19. Zygmunt A, Stanczyk J. Methods of evaluation of autonomic nervous system function. Arch Med Sci

Cite this article as: Jeong SC, Kim JJ, Kim YH, Kim IS, Han JW, Moon SW. Heart rate variability as a potential diagnostic tool to predict compensatory hyperhidrosis after sympathectomy in patients with primary focal hyperhidrosis. J Thorac Dis 2020;12(11):6789-6796. doi: 10.21037/jtd-20-2038
2010;6:11-8.

20. Fiorelli A, Messina G, Chiodini P, et al. Cardiac Autonomic Changes After Thoracic Sympathectomy: A Prospective, Randomized Study. Ann Thorac Surg 2017;103:216-24.

21. Bygstad E, Terkelsen AJ, Pilegaard HK, et al. Thoracoscopic sympathectomy increases efferent cardiac vagal activity and baroreceptor sensitivity. Eur J Cardiothorac Surg 2013;44:e193-9.

22. Zhang TY, Wang L, Xu JJ. The effects of thoracic sympathotomy on heart rate variability in patients with palmar hyperhidrosis. Yonsei Med J 2012;53:1081-4.

23. Fiorelli A, D'Aponte A, Canonico R, et al. T2-T3 sympathectomy versus sympathicotomy for essential palmar hyperhidrosis: comparison of effects on cardio-respiratory function. Eur J Cardiothorac Surg 2012;42:454-61.

24. Schmidt JE, Wehrwein EA, Gronbach LA, et al. Autonomic function following endoscopic thoracic sympathotomy for hyperhidrosis. Clin Auton Res 2011;21:11-7.

25. Schwartz PJ, La Rovere MT, De Ferrari GM, et al. Autonomic modulation for the management of patients with chronic heart failure. Circ Heart Fail 2015;8:619-28.

26. Kargi AB. Plantar Sweating as an Indicator of Lower Risk of Compensatory Sweating after Thoracic Sympathectomy. Thorac Cardiovasc Surg 2017;65:479-83. 